\title{
The importance of components of pulmonary rehabilitation, other than exercise training, in COPD
}

\author{
Kylie Hill' ${ }^{1,2,3}$, loannis Vogiatzis $s^{4,5}$ and Chris Burtin 6,7 \\ Number 2 in the Series "Thematic Review Series on Pulmonary Rehabilitation" \\ Edited by M.A. Spruit and E.M. Clini
}

\begin{abstract}
Affiliations: 'School of Physiotherapy and Exercise Science, Curtin University, Perth, ${ }^{2}$ Lung Institute of Western Australia and Centre for Asthma, Allergy and Respiratory Research, University of Western Australia, Perth, and ${ }^{3}$ Physiotherapy Dept, Royal Perth Hospital, Perth, Australia. ${ }^{4} 1$ st Dept of Respiratory Medicine, National and Kapodistrian University of Athens, Athens, Greece. ${ }^{5}$ Institute for Clinical Exercise and Health Science, University of the West of Scotland, Hamilton, UK. ' ${ }^{6}$ Dept of Allied Health Professions, Fontys University of Applied Sciences, Eindhoven, The Netherlands. ${ }^{7}$ Dept of Rehabilitation Sciences, Katholieke Universiteit Leuven, Leuven, Belgium.
\end{abstract}

Correspondence: K. Hill, School of Physiotherapy and Exercise Science, GPO Box U1987, Perth, Western Australia 6845, Australia. E-mail: K. Hillacurtin.edu.au

ABSTRACT Comprehensive pulmonary rehabilitation is an important component in the clinical management of people with chronic obstructive pulmonary disease (COPD). Although supervised exercise training is considered the cornerstone of effective pulmonary rehabilitation, there are many other components that should be considered to manage the impairments and symptom burden, as well as the psychosocial and lifestyle changes imposed by COPD. These include approaches designed to: 1) facilitate smoking cessation; 2) optimise pharmacotherapy; 3) assist with early identification and treatment of acute exacerbations; 4) manage acute dyspnoea; 5) increase physical activity; 6) improve body composition; 7) promote mental health; 8) facilitate advance care planning; and 9) establish social support networks. This article will describe these approaches, which may be incorporated within pulmonary rehabilitation, to optimise effective chronic disease self-management.

@ERSpublications

This paper describes several components of comprehensive pulmonary rehabilitation, other than simply exercise training http://ow.ly/mMNRp

\section{Pulmonary rehabilitation for chronic obstructive pulmonary disease}

Chronic obstructive pulmonary disease (COPD) is characterised by persistent airflow limitation due to chronic inflammation within the airways and lung in response to noxious particles or gases [1]. People with this condition are limited by dyspnoea and have impaired exercise capacity and health-related quality of life [1]. The prevalence of COPD amongst adults aged $\geqslant 40$ years is $\sim 10 \%$ [2], and increases to $21 \%$ in those with a significant smoking history who are visiting their family physician for any reason [3]. The natural course of COPD is punctuated with episodes of acute worsening, known as exacerbations, which contribute

Previous articles in this Series: No. 1: Gloeckl R, Marinov B, Pitta F. Practical recommendations for exercise training in patients with COPD. Eur Respir Rev 2013; 22: 178-186.

Received: May 092013 | Accepted after revision: June 102013

Conflict of interest: None declared.

Provenance: Submitted article, peer reviewed.

Copyright @ERS 2013 
to the burden and mortality associated with the disease $[4,5]$. By 2020, it is estimated that COPD will be the fifth most burdensome disease and third leading cause of mortality worldwide [1].

Pulmonary rehabilitation is considered an important component in the clinical management of people with COPD. The American Thoracic Society/European Respiratory Society have recently defined pulmonary rehabilitation as "a comprehensive intervention based on a thorough patient assessment followed by patient-tailored therapies, which include, but are not limited to, exercise training, education and behaviour change, designed to improve the physical and psychological condition of people with chronic respiratory disease and to promote the long-term adherence to health-enhancing behaviours" [6]. As such, pulmonary rehabilitation represents an ideal opportunity to facilitate chronic disease self-management (CDSM) by people with COPD. Specifically, CDSM aims to promote a person's ability to manage their condition collaboratively with healthcare providers to improve their well-being [7]. Goals of CDSM may include minimising symptoms and optimising treatment, as well as managing the physical, psychosocial and lifestyle changes imposed by a chronic condition [8]. This is achieved by facilitating effective patient-healthcare provider dialogues and empowering people to implement treatment regimens and changes in behaviour that optimise control of their condition and improve health outcomes [7,9]. Although education and training are inherent components of CDSM, the nature of the approaches that aim to effect long-term behavioural changes vary greatly [7]. A range of resources exist to assist healthcare professionals to promote CDSM (table 1), and this article will describe approaches that may be incorporated within a pulmonary rehabilitation programme. Approaches have been grouped as those designed to: 1) facilitate smoking cessation; 2) optimise pharmacotherapy; 3) assist with early identification and treatment of acute exacerbations; 4) manage acute dyspnoea; 5) increase physical activity; 6) improve body composition; and 7) promote mental health (fig. 1). The importance of advance care planning and establishing social support networks is also discussed.

\section{Facilitating smoking cessation}

As smoking cessation slows the rate of decline in lung function, improves symptoms and potentially reduces the number of exacerbations in people with COPD [10-13], addressing this issue is of utmost importance in current smokers entering pulmonary rehabilitation. Although some clinicians are not in favour of including current smokers in pulmonary rehabilitation [14], the gains that can be achieved in terms of exercise tolerance and health-related quality of life are similar between smokers and nonsmokers [15]. However, smokers are more likely to decline participation in pulmonary rehabilitation and attrition appears to be higher in those who continue to smoke [16].

Effective interventions to facilitate smoking cessation include counselling therapy by physicians or other healthcare professionals (e.g. a smoking-cessation specialist) and nicotine replacement therapy with transdermal patches, gums and nasal sprays [17]. Simple advice from the physician or the provision of selfhelp material is only marginally effective $[18,19]$. Combining counselling and nicotine replacement therapy appears to optimise success [20]. Smoking-cessation rates after 12 months of combined interventions in people with COPD range from $15 \%$ to $35 \%$ [21, 22]. There is a strong dose-response relationship between the intensity of counselling therapy and its effectiveness [1]. When added to a 3-month rehabilitation programme, individual counselling and nicotine replacement therapy yielded a smoking cessation rate of $68 \%$ at 12 months. This was considerably greater than that reported in a group that received individual counselling and nicotine replacement therapy without rehabilitation (32\%) [23]. Although these results should be interpreted with care due to the study design (i.e. a nonrandomised trial), the findings confirm that a smoking cessation intervention embedded with a pulmonary rehabilitation programme is a promising approach.

TABLE 1 Resources to assist with education and self-management training for patients with chronic obstructive pulmonary disease (COPD)

Developer

Website

\section{McGill University Health Centre and Quebec Asthma and COPD Network Lung Foundation Australia}

European Lung Foundation American Lung Association British Lung Foundation www.livingwellwithcopd.com

www.lungfoundation.com.au/professional-resources/pulmonary-rehabilitation/better-livingwith-copd-a-patient-guide/

www.european-lung-foundation.org/53-european-lung-foundation-elf-resources.htm www.lung.org/lung-disease/copd/living-with-copd/copd-management-tools.html www.blf.org.uk/Conditions/Detail/COPD 


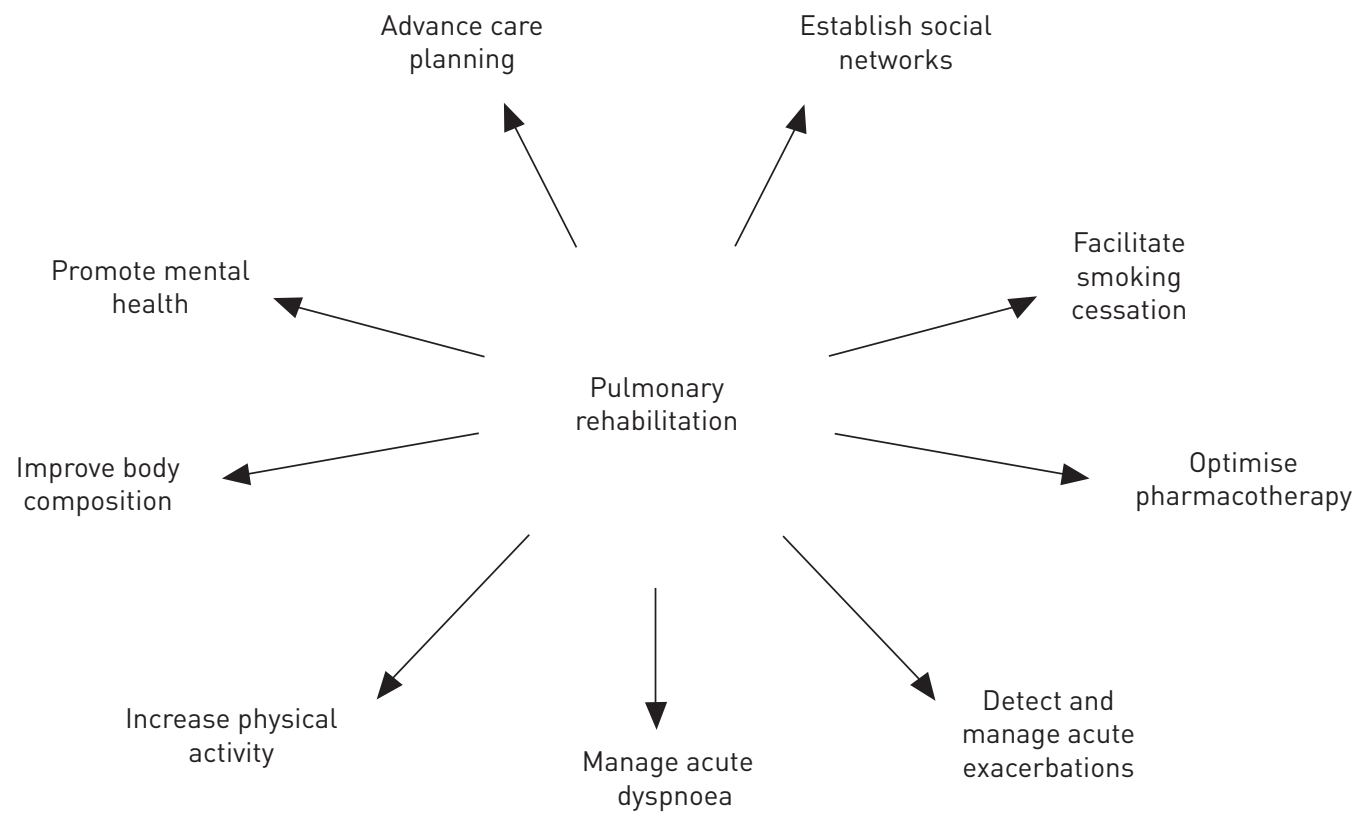

FIGURE 1 Components and goals of pulmonary rehabilitation other than exercise training.

\section{Optimising pharmacotherapy}

Providing instruction and training regarding medication use is an important component of CDSM. Specifically, appropriate respiratory medication use, which includes correct inhaler technique, as well as influenza and pneumococcal vaccines, has been shown to reduce exacerbations and hospitalisations in people with COPD [24-26]. Nevertheless, there appear to be important gaps in the knowledge regarding medication use by people with COPD enrolled in pulmonary rehabilitation [27]. Information related to oxygen therapy was also reported to be of interest [27] and should aim to increase adherence to long-term oxygen therapy by those with marked hypoxaemia at rest, as this may confer a survival benefit [28, 29]. Furthermore, there is now recognition of the prevalence of multi-comorbidity amongst people with COPD. That is, more than half of all people with COPD who have been referred to a pulmonary rehabilitation programme have at least one other chronic condition [30] and, therefore, medication burden in this group is likely to be high. Among elderly adults who have been prescribed multiple medications, nonadherence to pharmacotherapy regimens is problematic [31], which, in turn, increases the risk of hospitalisation and mortality [32]. Thus pulmonary rehabilitation offers the opportunity to review medication use and implement strategies to optimise adherence.

\section{Assisting with early detection and treatment of acute exacerbations}

Despite the detrimental impact of acute exacerbations on the course of the disease, people with COPD often have difficulty recognising the symptoms of an exacerbation early after the onset [33]. This leads to underreporting of exacerbations [34]. Time to symptom recovery increases by 0.4 days for every day that there is a delay in seeking therapy [35]. Written action plans for acute exacerbations that emphasise prompt initiation of individualised medical treatment at the onset of symptoms have been described in the literature $[9,35]$, and are associated with a diminished impact of the exacerbations on health status [36] and shorter recovery time in terms of symptoms [36-38]. People using these action plans appear to seek treatment earlier during the course of an acute exacerbation [38]. These strategies, however, do not result in a decrease of exacerbation frequency $[36,37]$. Conflicting results have been published concerning the influence on healthcare utilisation. EFFING et al. [37] reported that action plans were a cost-effective intervention leading to a reduction of healthcare contacts, while others report no effects on the use of healthcare resources [36]. In line with this, BIsCHOFF et al. [39] investigated more comprehensive self-management strategies, including education, and reported no difference in unscheduled medical contacts. Interestingly, action plans increased the use of oral corticosteroids and antibiotics $[37,39,40]$. The observation that increased use of medication is not clearly translated into decreased use of healthcare resources triggers the question to what extent people make inappropriate use of medication as stated in action plans.

Although, at first sight, written action plans embedded in self-management programmes appear to be simple, cheap and effective interventions, it has to be noted that studies showing positive effects generally 
included case managers that were always available for the participants $[9,36,39,40]$. Consequently, it is unclear to what extent the continuous access to a case manager played a role in the results of these trials.

Pulmonary rehabilitation programmes initiated immediately following an acute exacerbation typically include self-management strategies and are effective at decreasing rehospitalisation rate [41]. However, it is not clear whether the self-management programmes had an additional advantage in decreasing rehospitalisation rate over and above other components of pulmonary rehabilitation, such as supervised exercise training.

\section{Managing acute dyspnoea}

Dyspnoea is the most disabling symptom for people with COPD and is often the reason that medical attention is sought [1]. Strategies that have been demonstrated to ameliorate dyspnoea, other than participating in supervised exercise training, include adopting a forward-lean sitting position, pursed lip breathing and the use of a rollator (or four-wheeled walker) to assist with ambulation. Specifically, the forward-lean position optimises the mechanical advantage and pressure-generating capacity of the inspiratory muscles, namely the diaphragm [42]. This, in turn, is likely to reduce the sensation of unrewarded inspiration (perceived as dyspnoea) that arises from disequilibrium between the efferent outflow to the inspiratory muscles and the corresponding afferent input from the respiratory system receptors [43]. The reduction in dyspnoea perceived with pursed-lip breathing seems to relate to a slowing of the respiratory rate, which, in people with expiratory airflow obstruction, allows for more complete lung emptying during expiration and less pulmonary hyperinflation [44-46]. Finally, the use of a rollator allows people to fix their upper limbs during ambulation and reduces their dyspnoea [47], presumably by facilitating use of the accessory muscles of respiration and minimising reliance on the diaphragm during inspiration. Fixing the upper limbs on a rollator has been shown to confer significant increases in maximum voluntary ventilation $[48,49]$. Furthermore, compared with walking unaided, the use of a rollator reduces the metabolic cost of walking for many people with COPD [50]. These strategies are useful to implement within the context of pulmonary rehabilitation, as people have the opportunity to utilise them during periods of increased dyspnoea associated with supervised exercise training.

\section{Increasing physical activity}

Promotion of physical activity has become a priority for healthcare authorities in the industrialised world. Information on the importance of physical activity promotion in COPD has grown, especially in the past few years [51]. People with COPD are physically inactive and this inactivity is detrimental to their health. That is, low levels of physical activity have been related to an increased risk of hospital admissions and mortality $[52,53]$.

There is an emerging need for interventions that confer a sustainable lifestyle change characterised by increased physical activity and less sedentary behaviour during daily life in people with COPD [54]. Interestingly, physical activity levels correlate better with measures of functional exercise capacity, such as the 6-min walking distance, than with abnormalities in pulmonary function and, therefore, optimising exercise capacity may assist in promoting physical activity levels. In addition to exercise training, pulmonary rehabilitation should incorporate specific interventions to increase daily physical activity [55], such as goal setting. As physical activity is recognised as a multifaceted behaviour that involves frequency, intensity, time and type, these variables constitute modifiable dimensions [56].

Daily physical activity should be encouraged in addition to the promotion of the light intensity activities that are frequently performed during daily life. It is of note that the proportion of people achieving the recommended physical activity levels is greater when shorter bouts of activities are grouped together, rather than when definitions are restricted to consecutive minutes. Fulfilling the recommendations for physical activity with short bouts may be more feasible and not necessarily less effective. This is supported by clinical trials demonstrating similar effects in aerobic fitness, weight loss and other cardiovascular risk factors with either long bouts $(\geqslant 20 \mathrm{~min}$ ) or short bouts $(\geqslant 10 \mathrm{~min}$ ) of physical activity [57].

It is interesting to note that the way people with COPD seem to adapt to exercise limitation matches with the strategy of interval exercise that is used in pulmonary rehabilitation, in particular in those with the most severe disease. DONAIRE-GONZALEZ et al. [58] showed that people with COPD across a wide range of disease severity engage in physical activity bouts of moderate-to-vigorous intensities. People with severe and very severe COPD perform their daily activities in fewer and shorter bouts than those with mild or moderate disease [58]. Therefore, a meaningful focus of rehabilitation programmes could be to increase the frequency of bouts of physical activity rather than prolonging the duration of such bouts.

PITTA et al. [59] examined activity levels after 3 and 6 months of ongoing rehabilitation in 41 people with COPD and found that, overall, walking time improved marginally at 3 months but improved significantly 
more at the 6-month time-point. This was despite early significant improvements in maximal exercise capacity. The benefits were greatest in those people with better adherence to the training sessions [59]. Others have shown early increased daily activity after short-term rehabilitation, but the magnitude of the change appears to be small [60]. Long-term maintenance of any increase is challenging. Strategies such as regular telephone support and follow-up visits may be insufficient [61]. It is likely that sustained gains in physical activity and/or reductions in sedentary behaviour in this population will require complex interventions that may include exercise training, goal setting and motivational interviewing.

\section{Improving body composition}

Although COPD is characterised by progressive and persistent airway obstruction, there are innumerable complications that occur during the progression of the disease that can affect the nutritional state of people with this condition [62]. Bodyweight and body mass index (BMI) are important and easy-to-measure markers of nutritional status that correlate strongly with prognosis in people with COPD; however, they can clearly underestimate the prevalence of nutritional impairment in this condition. Body composition studies using a variety of methods have shown that depletion of fat-free mass (FFM) occurs in a substantial proportion of people with COPD, even in the absence of weight loss [63, 64].

Malnutrition is associated with a poor prognosis for people with COPD, as it predisposes them to infections, presumably due to decreased cell-mediated immunity and poor wound healing [65]. It may also limit the ability to produce surfactant, lead to reduced protein synthesis, affect the functioning of peripheral muscles and reduce respiratory muscle force, exercise tolerance and health-related quality of life $[62,65]$. Resting energy expenditure is higher in people with COPD with weight loss, which is due, at least in part, to an increased load imposed on respiratory muscles, which may contribute to the onset of acute respiratory ailure $[66,67]$. Taken together, the deleterious consequences of malnutrition and weight loss assist to explain the findings of a number of observational studies, namely that a low BMI is associated with a poor prognosis independent of the degree of ventilatory impairment [68]. Weight loss and, perhaps more importantly, the loss of lean body mass, are significant indicators of disease progression in COPD. Indeed, there is strong evidence that weight loss in people with COPD is associated with increased mortality $[68,69]$.

Nutritional support is, therefore, an important part of therapy for the stable outpatients and for people with COPD who are hospitalised, including those in the intensive care unit. The nutritional programme should follow an assessment of the nutritional status. With a correct composition of nutrients and calories, it is possible to improve the nutrition of people in the different clinical stages of the disease [65]. Most of the clinical trials to date have shown that short-term oral nutritional supplementation can result in increases in body weight and, in some, measures of muscle strength [63]. For example, PLANAs et al. [70] found that administration of nutritional supplements conferred significant improvements in body weight and tended to reduce airflow limitation and increase handgrip strength and health-related quality of life. When combined with an exercise programme, nutritional support not only increased body weight but also resulted in significant improvements in FFM, respiratory and peripheral muscle strength, exercise capacity and health status $[71,72]$. Thus, a combination of nutritional support and exercise as an anabolic stimulus appears to be the best approach and people responding to this treatment may confer a survival benefit [73]. As optimising nutritional status could delay the progression of COPD and might also reduce the risk of early mortality, nutritional support has been advocated as a useful part of care for people with COPD, especially those with a low BMI $[6,68,74]$.

In addition to a low BMI, it is important to note that, in many parts of the world, the prevalence of obesity is increasing at an alarming rate. Obesity is clearly linked to specific clusters of comorbidities, such as cardiovascular, cachectic, metabolic and psychological conditions [75], and is a risk factor for reduced survival, independent of smoking status [76]. Paradoxically, epidemiological studies have shown that people with advanced COPD who are overweight or mildly to moderately obese have a survival advantage compared with their underweight counterparts $[77,78]$. This "obesity paradox" has also been described in other chronic diseases but the protective mechanisms are unknown. However, weight reduction is undoubtedly the optimal health strategy for obese patients with chronic respiratory disease. In general, therapy comprising diet, physical activity and medication promotes a moderate degree of weight or fat loss in the short term $[79,80]$.

\section{Promoting mental health}

A large proportion of people with COPD report feelings of anxiety and depression. Although prevalence estimates for these comorbidities vary greatly due to differences in sampling and the use of different instruments [81], a prevalence of $36 \%$ for anxiety and $40 \%$ for depression appears to be a valid estimate [82]. The incidence of depression in people with COPD is 2.5 times higher compared with the healthy 
elderly [83]. People with depression have a greater risk for exacerbations [84], rehospitalisation and mortality [85]. Within a multidisciplinary rehabilitation team, psychologists are the best placed healthcare professionals to provide specific treatment for people with symptoms of anxiety and/or depression. Notably, psychotherapy implemented during pulmonary rehabilitation improves symptoms of anxiety and depression [86].

Cognitive-behavioural therapy (CBT) is a structured psychological intervention that has been frequently used in people with symptoms of anxiety and depression. This intervention combines cognitive psychotherapy with behavioural therapy and maintains that irrational beliefs and distorted attitudes toward the self, the environment, and the future perpetuate depressive affects and compromise functioning [87]. The goal of CBT is to reduce depressive symptoms by challenging and reversing these beliefs and attitudes and encouraging people to change their maladaptive preconceptions and behaviours in real life [87]. Although CBT has been shown to reduce symptoms of anxiety and depression in elderly populations $[88,89]$, the evidence in people with COPD is rather limited [90]. A review based on small studies in people with COPD suggests that there is only limited evidence that CBT is effective in reducing symptoms of anxiety and depression when added to exercise and education [91].

\section{Advance care planning}

Advance care planning is the process of determining a person's values and preferences for future management of their condition, which includes end-of-life care [92]. An understanding of these issues has the potential to mitigate unwanted interventions, such as intubation and ventilation, and has been shown to reduce psychological stress for both patients and carers $[93,94]$. Despite the fact that chronic lung diseases, such as COPD, are a leading cause of mortality worldwide, the issue of advance care planning is often poorly addressed as part of their clinical management [95-97]. Advance care planning for people with end-stage cardiorespiratory disease is considered challenging, as the disease progression is often variable and gradual, hospitalisations are episodic, prognosis may be unclear and people may not recognise the seriousness of their condition [95]. Earlier work has shown that people with COPD were eager for discussions while in a stable state of health $[98,99]$ and that nonmedical facilitators are an acceptable source of information. As pulmonary rehabilitation involves people with COPD working closely with healthcare professionals over several weeks, it is likely that these programmes are an appropriate forum to commence discussions pertaining to advance care planning [100].

\section{Establishing social support networks}

A feeling of social isolation is commonly expressed by people with COPD [101, 102]. Impaired exercise tolerance and excessive feelings of dyspnoea during activities result in decreased physical activity levels [103], and people become more homebound as they decrease participation in outdoor activities. Social contacts diminish and people are frequently afraid to become dependent on others. Pulmonary rehabilitation can provide an environment that reinforces the social contacts and support. Those who participate in pulmonary rehabilitation report enjoying the social aspect of training together [104], and people can interact, receive and provide emotional support, which serves to encourage and motivate one another [104]. Furthermore, exercising in a peer group and opportunities for social interaction are important components for a long-term physically active lifestyle [105]. Besides the people with COPD, the caregivers might also find the desired social support in the pulmonary rehabilitation setting [106].

Outside of the context of pulmonary rehabilitation, patient support groups assist people in dealing with their disease and taking an active role in their disease management. It offers a place to share thoughts, experiences, support and friendship with peers who experience the same barriers and problems. Generally these groups are organised by people with COPD, but may be facilitated by respiratory health professionals. People with COPD should be encouraged to take part in a local support group over the course of their rehabilitation programme [107].

\section{Conclusions}

Although supervised exercise training is considered the cornerstone of effective pulmonary rehabilitation [108], there are many other approaches that may help to manage the impairments and symptom burden, as well as the psychosocial and lifestyle changes imposed by COPD. Consideration should be given to incorporating these approaches within the framework of a comprehensive pulmonary rehabilitation programme, with the goal of promoting effective life-long CDSM. A comprehensive multidisciplinary team can provide a tailor-made intervention, with the patient having access to those healthcare professionals with expertise that is relevant for their specific situation. Regular multidisciplinary team meetings may help healthcare professionals to provide a coordinated approach to patient care. 


\section{References}

1 Vestbo J, Hurd SS, Agusti AG, et al. Global Strategy for the Diagnosis, Management, and Prevention of Chronic Obstructive Pulmonary Disease: GOLD Executive Summary. Am J Respir Crit Care Med 2013; 187: 347-365.

2 Buist AS, McBurnie MA, Vollmer WM, et al. International variation in the prevalence of COPD (the BOLD Study): a population-based prevalence study. Lancet 2007; 370: 741-750.

3 Hill K, Goldstein RS, Guyatt GH, et al. Prevalence and underdiagnosis of chronic obstructive pulmonary disease among patients at risk in primary care. CMAJ 2010; 182: 673-678.

4 Hurst JR, Vestbo J, Anzueto A, et al. Susceptibility to exacerbation in chronic obstructive pulmonary disease. $N$ Engl J Med 2010; 363: 1128-1138.

5 Garcia-Aymerich J, Serra Pons I, Mannino DM, et al. Lung function impairment, COPD hospitalisations and subsequent mortality. Thorax 2011; 66: 585-590.

6 Spruit MA, Singh SJ, Garvey C, et al. An Official American Thoracic Society/European Respiratory Society statement: key concepts and advances in pulmonary rehabilitation - an executive summary. Am J Respir Crit Care Med (in press).

7 Effing TW, Bourbeau J, Vercoulen J, et al. Self-management programmes for COPD: moving forward. Chron Respir Dis 2012; 9: 27-35.

8 Barlow J, Wright C, Sheasby J, et al. Self-management approaches for people with chronic conditions: a review. Patient Educ Couns 2002; 48: 177-187.

9 Bourbeau J, Julien M, Maltais F, et al. Reduction of hospital utilization in patients with chronic obstructive pulmonary disease: a disease-specific self-management intervention. Arch Intern Med 2003; 163: 585-591.

10 Connett JE, Murray RP, Buist AS, et al. Changes in smoking status affect women more than men: results of the Lung Health Study. Am J Epidemiol 2003; 157: 973-979.

11 Kanner RE, Connett JE, Williams DE, et al. Effects of randomized assignment to a smoking cessation intervention and changes in smoking habits on respiratory symptoms in smokers with early chronic obstructive pulmonary disease: the Lung Health Study. Am J Med 1999; 106: 410-416.

12 Scanlon PD, Connett JE, Waller LA, et al. Smoking cessation and lung function in mild-to-moderate chronic obstructive pulmonary disease. The Lung Health Study. Am J Respir Crit Care Med 2000; 161: 381-390.

13 Makris D, Moschandreas J, Damianaki A, et al. Exacerbations and lung function decline in COPD: new insights in current and ex-smokers. Respir Med 2007; 101: 1305-1312.

14 Lacasse Y, Maltais F, Goldstein RS. Smoking cessation in pulmonary rehabilitation: goal or prerequisite? J Cardiopulm Rehabil 2002; 22: 148-153.

15 Nici L, Donner C, Wouters E, et al. American Thoracic Society/European Respiratory Society statement on pulmonary rehabilitation. Am J Respir Crit Care Med 2006; 173: 1390-1413.

16 Young P, Dewse M, Fergusson W, et al. Respiratory rehabilitation in chronic obstructive pulmonary disease: predictors of nonadherence. Eur Respir J 1999; 13: 855-859.

17 Tonnesen P. Smoking cessation and COPD. Eur Respir Rev 2013; 22: 37-43.

18 Lancaster T, Stead L. Physician advice for smoking cessation. Cochrane Database Syst Rev 2004; 4: CD000165.

19 Lancaster T, Stead LF. Self-help interventions for smoking cessation. Cochrane Database Syst Rev 2005; 3: CD001118.

20 Strassmann R, Bausch B, Spaar A, et al. Smoking cessation interventions in COPD: a network meta-analysis of randomised trials. Eur Respir J 2009; 34: 634-640.

21 Anthonisen NR, Connett JE, Kiley JP, et al. Effects of smoking intervention and the use of an inhaled anticholinergic bronchodilator on the rate of decline of FEV1. The Lung Health Study. JAMA 1994; 272: 1497-1505.

22 Tonnesen P, Mikkelsen K, Bremann L. Nurse-conducted smoking cessation in patients with COPD using nicotine sublingual tablets and behavioral support. Chest 2006; 130: 334-342.

23 Paone G, Serpilli M, Girardi E, et al. The combination of a smoking cessation programme with rehabilitation increases stop-smoking rate. J Rehabil Med 2008; 40: 672-677.

24 Poole PJ, Chacko E, Wood-Baker RW, et al. Influenza vaccine for patients with chronic obstructive pulmonary disease. Cochrane Database Syst Rev 2006; 1: CD002733.

25 Calverley PM, Rabe KF, Goehring UM, et al. Roflumilast in symptomatic chronic obstructive pulmonary disease: two randomised clinical trials. Lancet 2009; 374: 685-694.

26 Decramer M, Celli B, Kesten S, et al. Effect of tiotropium on outcomes in patients with moderate chronic obstructive pulmonary disease (UPLIFT): a prespecified subgroup analysis of a randomised controlled trial. Lancet 2009; 374: 1171-1178.

27 Wilson JS, O'Neill B, Reilly J, et al. Education in pulmonary rehabilitation: the patient's perspective. Arch Phys Med Rehabil 2007; 88: 1704-1709.

28 Continuous or nocturnal oxygen therapy in hypoxemic chronic obstructive lung disease: a clinical trial. Nocturnal Oxygen Therapy Trial Group. Ann Intern Med 1980; 93: 391-398.

29 Long term domiciliary oxygen therapy in chronic hypoxic cor pulmonale complicating chronic bronchitis and emphysema. Report of the Medical Research Council Working Party. Lancet 1981; 1: 681-686.

30 Crisafulli E, Costi S, Luppi F, et al. Role of comorbidities in a cohort of patients with COPD undergoing pulmonary rehabilitation. Thorax 2008; 63: 487-492.

31 Wilson IB, Schoen C, Neuman P, et al. Physician-patient communication about prescription medication nonadherence: a 50-state study of America's seniors. J Gen Intern Med 2007; 22: 6-12.

32 Vestbo J, Anderson JA, Calverley PM, et al. Adherence to inhaled therapy, mortality and hospital admission in COPD. Thorax 2009; 64: 939-943.

33 Kessler R, Stahl E, Vogelmeier C, et al. Patient understanding, detection, and experience of COPD exacerbations: an observational, interview-based study. Chest 2006; 130: 133-142.

34 Langsetmo L, Platt RW, Ernst P, et al. Underreporting exacerbation of chronic obstructive pulmonary disease in a longitudinal cohort. Am J Respir Crit Care Med 2008; 177: 396-401.

35 Wilkinson TM, Donaldson GC, Hurst JR, et al. Early therapy improves outcomes of exacerbations of chronic obstructive pulmonary disease. Am J Respir Crit Care Med 2004; 169: 1298-1303. 
Trappenburg JC, Monninkhof EM, Bourbeau J, et al. Effect of an action plan with ongoing support by a case manager on exacerbation-related outcome in patients with COPD: a multicentre randomised controlled trial. Thorax 2011; 66: 977-984.

37 Effing T, Kerstjens H, van der Valk P, et al. (Cost)-effectiveness of self-treatment of exacerbations on the severity of exacerbations in patients with COPD: the COPE II study. Thorax 2009; 64: 956-962.

38 Effing T. Action plans and case manager support may hasten recovery of symptoms following an acute exacerbation in patients with chronic obstructive pulmonary disease (COPD). J Physiother 2012; 58: 60.

39 Bischoff EW, Akkermans R, Bourbeau J, et al. Comprehensive self management and routine monitoring in chronic obstructive pulmonary disease patients in general practice: randomised controlled trial. BMJ 2012; 345 : e7642.

40 Effing T, Monninkhof EM, van der Valk PD, et al. Self-management education for patients with chronic obstructive pulmonary disease. Cochrane Database Syst Rev 2007; 4: CD002990.

41 Puhan M, Scharplatz M, Troosters T, et al. Pulmonary rehabilitation following exacerbations of chronic obstructive pulmonary disease. Cochrane Database Syst Rev 2009; 1: CD005305.

42 O'Neill S, McCarthy DS. Postural relief of dyspnoea in severe chronic airflow limitation: relationship to respiratory muscle strength. Thorax 1983; 38: 595-600.

43 Parshall MB, Schwartzstein RM, Adams L, et al. An official American Thoracic Society statement: update on the mechanisms, assessment, and management of dyspnea. Am J Respir Crit Care Med 2012; 185: 435-452.

44 Breslin EH. The pattern of respiratory muscle recruitment during pursed-lip breathing. Chest 1992; 101: 75-78.

45 Bianchi R, Gigliotti F, Romagnoli I, et al. Chest wall kinematics and breathlessness during pursed-lip breathing in patients with COPD. Chest 2004; 125: 459-465.

46 Garrod R, Dallimore K, Cook J, et al. An evaluation of the acute impact of pursed lips breathing on walking distance in nonspontaneous pursed lips breathing chronic obstructive pulmonary disease patients. Chron Respir Dis 2005; 2: 67-72.

47 Solway S, Brooks D, Lau L, et al. The short-term effect of a rollator on functional exercise capacity among individuals with severe COPD. Chest 2002; 122: 56-65.

48 Probst VS, Troosters T, Coosemans I, et al. Mechanisms of improvement in exercise capacity using a rollator in patients with COPD. Chest 2004; 126: 1102-1107.

49 Cavalheri V, Camillo CA, Brunetto AF, et al. Effects of arm bracing posture on respiratory muscle strength and pulmonary function in patients with chronic obstructive pulmonary disease. Rev Port Pneumol 2010; 16: 887-891.

50 Hill K, Dolmage TE, Woon LJ, et al. Rollator use does not consistently change the metabolic cost of walking in people with chronic obstructive pulmonary disease. Arch Phys Med Rehabil 2012; 93: 1077-1080.

51 Esteban C. Role of physical activity in chronic obstructive pulmonary disease. Arch Bronconeumol 2009; 45: Suppl. $5,7-13$

52 Pitta F, Troosters T, Probst VS, et al. Physical activity and hospitalization for exacerbation of COPD. Chest 2006; 129: 536-544.

53 Garcia-Aymerich J, Lange P, Benet M, et al. Regular physical activity reduces hospital admission and mortality in chronic obstructive pulmonary disease: a population based cohort study. Thorax 2006; 61: 772-778.

54 Nelson ME, Rejeski WJ, Blair SN, et al. Physical activity and public health in older adults: recommendation from the American College of Sports Medicine and the American Heart Association. Med Sci Sports Exerc 2007; 39: 1435-1445.

55 Zuwallack RL. How do we increase activity and participation in our patients? Semin Respir Crit Care Med 2009; 30: 708-712.

56 Barisic A, Leatherdale ST, Kreiger N. Importance of frequency, intensity, time and type (FITT) in physical activity assessment for epidemiological research. Can J Public Health 2011; 102: 174-175.

57 Murtagh EM, Boreham CA, Nevill A, et al. The effects of 60 minutes of brisk walking per week, accumulated in two different patterns, on cardiovascular risk. Prev Med 2005; 41: 92-97.

58 Donaire-Gonzalez D, Gimeno-Santos E, Balcells E, et al. Physical activity in COPD patients: patterns and bouts. Eur Respir J 2012 [In press DOI: 10.1183/09031936.00101512].

59 Pitta F, Troosters T, Probst VS, et al. Are patients with COPD more active after pulmonary rehabilitation? Chest 2008; 134: 273-280.

60 Cindy Ng LW, Mackney J, Jenkins S, et al. Does exercise training change physical activity in people with COPD? A systematic review and meta-analysis. Chron Respir Dis 2012; 9: 17-26.

61 Guell R, Casan P, Belda J, et al. Long-term effects of outpatient rehabilitation of COPD: a randomized trial. Chest 2000; 117: 976-983.

62 Fernandes AC, Bezerra OM. Nutrition therapy for chronic obstructive pulmonary disease and related nutritional complications. J Bras Pneumol 2006; 32: 461-471.

63 Mallampalli A. Nutritional management of the patient with chronic obstructive pulmonary disease. Nutr Clin Pract 2004; 19: 550-556.

64 Schols AM, Soeters PB, Dingemans AM, et al. Prevalence and characteristics of nutritional depletion in patients with stable COPD eligible for pulmonary rehabilitation. Am Rev Respir Dis 1993; 147: 1151-1156.

65 Pezza M, Iermano C, Tufano R. Nutritional support for the patient with chronic obstructive pulmonary disease. Monaldi Arch Chest Dis 1994; 49: 33-39.

66 Donahoe M, Rogers RM, Wilson DO, et al. Oxygen consumption of the respiratory muscles in normal and in malnourished patients with chronic obstructive pulmonary disease. Am Rev Respir Dis 1989; 140: 385-391.

67 Laaban JP. Nutrition and chronic obstructive pulmonary disease. Rev Pneumol Clin 1991; 47: 235-250.

68 Prescott E, Almdal T, Mikkelsen KL, et al. Prognostic value of weight change in chronic obstructive pulmonary disease: results from the Copenhagen City Heart Study. Eur Respir J 2002; 20: 539-544.

69 Kim HC, Mofarrahi M, Hussain SN. Skeletal muscle dysfunction in patients with chronic obstructive pulmonary disease. Int J Chron Obstruct Pulmon Dis 2008; 3: 637-658.

70 Planas M, Alvarez J, Garcia-Peris PA, et al. Nutritional support and quality of life in stable chronic obstructive pulmonary disease (COPD) patients. Clin Nutr 2005; 24: 433-441.

71 Schols AM, Soeters PB, Mostert R, et al. Physiologic effects of nutritional support and anabolic steroids in patients with chronic obstructive pulmonary disease. A placebo-controlled randomized trial. Am J Respir Crit Care Med 1995; 152: 1268-1274. 
72 Creutzberg EC, Wouters EF, Mostert R, et al. Efficacy of nutritional supplementation therapy in depleted patients with chronic obstructive pulmonary disease. Nutrition 2003; 19: 120-127.

73 Schols A. Nutritional modulation as part of the integrated management of chronic obstructive pulmonary disease. Proc Nutr Soc 2003; 62: 783-791.

74 Raherison C, Girodet PO. Epidemiology of COPD. Eur Respir Rev 2009; 18: 213-221.

75 Vanfleteren LE, Spruit MA, Groenen M, et al. Clusters of comorbidities based on validated objective measurements and systemic inflammation in patients with chronic obstructive pulmonary disease. Am J Respir Crit Care Med 2013; 187: 728-735

76 O'Donnell DE, O'Donnell CD, Webb KA, et al. Respiratory consequences of mild-to-moderate obesity: impact on exercise performance in health and in chronic obstructive pulmonary disease. Pulm Med 2012; 2012: 818925.

77 Landbo C, Prescott E, Lange P, et al. Prognostic value of nutritional status in chronic obstructive pulmonary disease. Am J Respir Crit Care Med 1999; 160: 1856-1861.

78 Wilson DO, Rogers RM, Wright EC, et al. Body weight in chronic obstructive pulmonary disease. The National Institutes of Health Intermittent Positive-Pressure Breathing Trial. Am Rev Respir Dis 1989; 139: 1435-1438.

79 Poulain M, Doucet M, Major GC, et al. The effect of obesity on chronic respiratory diseases: pathophysiology and therapeutic strategies. CMAJ 2006; 174: 1293-1299.

80 Lessard A, Maltais F, Boulet LP. Clinical management of chronic obstructive pulmonary disease and asthma in an obese patient. Expert Opin Pharmacother 2008; 9: 83-93.

81 von Leupoldt A, Fritzsche A, Trueba AF, et al. Behavioral medicine approaches to chronic obstructive pulmonary disease. Ann Behav Med 2012; 44: 52-65.

82 Yohannes AM, Baldwin RC, Connolly MJ. Depression and anxiety in elderly outpatients with chronic obstructive pulmonary disease: prevalence, and validation of the BASDEC screening questionnaire. Int J Geriatr Psychiatry 2000; 15: 1090-1096.

83 van Manen JG, Bindels PJ, Dekker FW, et al. Risk of depression in patients with chronic obstructive pulmonary disease and its determinants. Thorax 2002; 57: 412-416.

84 Yohannes AM. Depression and sleep disorders predict acute exacerbations and hospitalization in patients with chronic obstructive pulmonary disease. Respirology 2012; 17: 1278.

85 Papaioannou AI, Bartziokas K, Tsikrika S, et al. The impact of depressive symptoms on recovery and outcome of hospitalised COPD exacerbations. Eur Respir J 2013; 41: 815-823.

86 de Godoy DV, de Godoy RF. A randomized controlled trial of the effect of psychotherapy on anxiety and depression in chronic obstructive pulmonary disease. Arch Phys Med Rehabil 2003; 84: 1154-1157.

87 Gelenberg AJ. A review of the current guidelines for depression treatment. J Clin Psychiatry 2010; 71: e15.

88 Gould RL, Coulson MC, Howard RJ. Efficacy of cognitive behavioral therapy for anxiety disorders in older people: a meta-analysis and meta-regression of randomized controlled trials. J Am Geriatr Soc 2012; 60: 218-229.

89 Gould RL, Coulson MC, Howard RJ. Cognitive behavioral therapy for depression in older people: a meta-analysis and meta-regression of randomized controlled trials. J Am Geriatr Soc 2012; 60: 1817-1830.

90 Cafarella PA, Effing TW, Usmani ZA, et al. Treatments for anxiety and depression in patients with chronic obstructive pulmonary disease: a literature review. Respirology 2012; 17: 627-638.

91 Coventry PA, Gellatly JL. Improving outcomes for COPD patients with mild-to-moderate anxiety and depression: a systematic review of cognitive behavioural therapy. Br J Health Psychol 2008; 13: 381-400.

92 Janssen DJ, Engelberg RA, Wouters EF, et al. Advance care planning for patients with COPD: past, present and future. Patient Educ Couns 2012; 86: 19-24.

93 Detering KM, Hancock AD, Reade MC, et al. The impact of advance care planning on end of life care in elderly patients: randomised controlled trial. BMJ 2010; 340: c1345.

94 Temel JS, Greer JA, Muzikansky A, et al. Early palliative care for patients with metastatic non-small-cell lung cancer. N Engl J Med 2010; 363: 733-742.

95 Exley C, Field D, Jones L, et al. Palliative care in the community for cancer and end-stage cardiorespiratory disease: the views of patients, lay-carers and health care professionals. Palliat Med 2005; 19: 76-83.

96 Janssen DJ, Curtis JR, Au DH, et al. Patient-clinician communication about end-of-life care for Dutch and US patients with COPD. Eur Respir J 2011; 38: 268-276.

97 Macpherson A, Walshe C, O'Donnell V, et al. The views of patients with severe chronic obstructive pulmonary disease on advance care planning: a qualitative study. Palliat Med 2013; 27: 265-272.

98 Heffner JE, Fahy B, Hilling L, et al. Attitudes regarding advance directives among patients in pulmonary rehabilitation. Am J Respir Crit Care Med 1996; 154: 1735-1740.

99 Gott M, Gardiner C, Small N, et al. Barriers to advance care planning in chronic obstructive pulmonary disease. Palliat Med 2009; 23: 642-648.

100 Burge AT, Lee A, Nicholes M, et al. Advance care planning education in pulmonary rehabilitation: a qualitative study exploring participant perspectives. Palliat Med 2013; 27: 508-515.

101 Wortz K, Cade A, Menard JR, et al. A qualitative study of patients' goals and expectations for self-management of COPD. Prim Care Respir J 2012; 21: 384-391.

102 Ellison L, Gask L, Bakerly ND, et al. Meeting the mental health needs of people with chronic obstructive pulmonary disease: a qualitative study. Chronic Illn 2012; 8: 308-320.

103 Watz H, Waschki B, Meyer T, et al. Physical activity in patients with COPD. Eur Respir J 2009; 33: 262-272.

104 Thorpe O, Johnston K, Kumar S. Barriers and enablers to physical activity participation in patients with COPD: a systematic review. J Cardiopulm Rehabil Prev 2012; 32: 359-369.

105 Hogg L, Grant A, Garrod R, et al. People with COPD perceive ongoing, structured and socially supportive exercise opportunities to be important for maintaining an active lifestyle following pulmonary rehabilitation: a qualitative study. J Physiother 2012; 58: 189-195.

106 Burton AM, Sautter JM, Tulsky JA, et al. Burden and well-being among a diverse sample of cancer, congestive heart failure, and chronic obstructive pulmonary disease caregivers. J Pain Symptom Manage 2012; 44: 410-420.

107 Jenkins S, Hill K, Cecins NM. State of the art: how to set up a pulmonary rehabilitation program. Respirology 2010; 15: 1157-1173.

108 Gloeckl R, Marinov B, Pitta F. Practical recommendations for exercise training in patients with COPD. Eur Respir Rev 2013; 22: 178-186. 